\title{
Women getting in and getting on
}

\author{
Modelling future trajectories in astrophysics finds it will take 60 years before women form even a third of academic \\ workforces. Targets and affirmative action reduce the wait, but systemic cultural change is needed for more \\ immediate equity.
}

\section{Pauline Leonard}

T he position of women in astrophysics shows little indication of improvement ${ }^{1,2}$. Across the globe, astronomy and physics departments and research institutions within academia present a depressingly homogeneous picture of sustained and high gender imbalance, particularly when compared to other disciplines within the arts and social sciences. Despite the introduction of various policy initiatives to improve the recruitment and career attainment levels of women in astrophysics and science, technology, engineering and mathematics subjects more generally, the under-representation of women remains endemic and systematic. In this issue of Nature Astronomy, Lisa Kewley shows that if current hiring practices and attrition rates are maintained, the fraction of women in Australian astrophysics will remain below $30 \%$ for at least 60 years ${ }^{3}$. Even in the most optimistic alternative scenario, gender parity won't be achieved for another 25 years. The length of time it will take to achieve a gender balanced workforce in astrophysics appears ignominious, and a radical rethinking of how institutions approach diversity is needed.

Australia is certainly no outlier here. Astronomy, astrophysics and physics are disciplines in which women, globally, are especially poorly represented ${ }^{4}$. For example, in the United States, of all sciences, these subjects have the lowest female participation rates: $21 \%$ of undergraduate students, $20 \%$ of $\mathrm{PhD}$ students and $16 \%$ of faculty members ${ }^{5}$. These percentages, which have not changed significantly for over a decade, are similar in the United Kingdom, with many European countries having even poorer ratios ${ }^{6}$. Why is the discipline so slow to change? Kewley argues that the root of the problem lies in attrition. Drawing on 2019 demographics data from the Mid-Term Review of the Australian Astronomy Decadal Plan (AADP), she defines a 'pipeline stress' statistic to establish that women leave Australian astronomy at at least three times the rate of men at the postdoc level and almost double the rate at associate professor level.

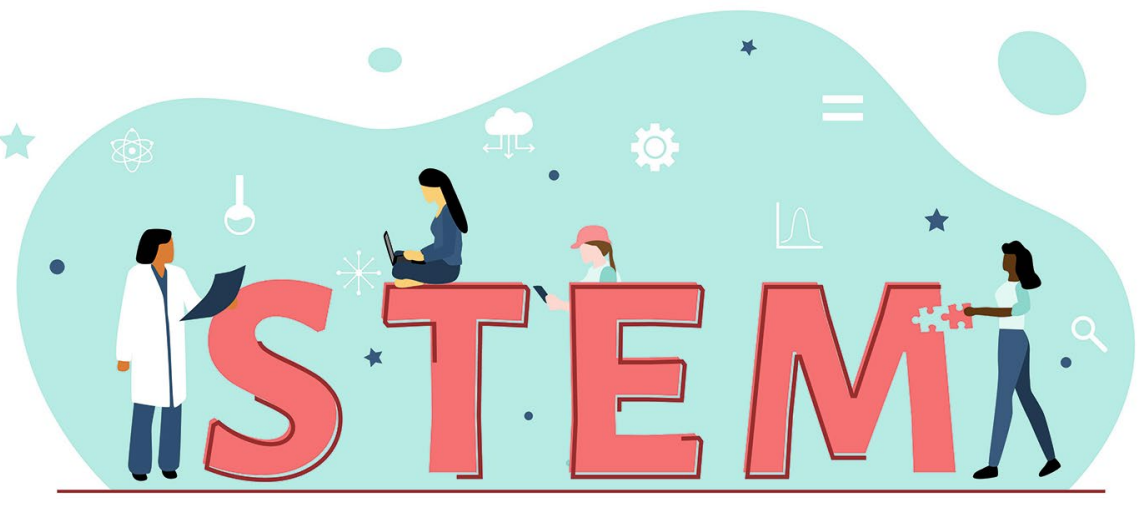

Credit: AdriVectors / Alamy Stock Vector

The strength of Kewley's study is to build data-driven nationwide gender workforce models to quantify the impact of the high levels of women leaving the profession and calculate how long it will take to meet each of the AADP's targets of $33 \%$ and, more ambitiously, 50\% women. Maintaining current promotion, hire, retirement and departure rates, her model reveals the targets cannot be achieved within 60 years, if ever. Yet while Kewley provides two alternative scenarios for change, neither bring much encouragement. The 'gender parity' initiative, whereby exactly equal numbers of women and men are hired, would achieve $33 \%$ women in 20 years. An 'affirmative action' approach, whereby 'women-only' positions are advertised to correct historic gender gaps, could achieve $33 \%$ women in 10 years and $50 \%$ in 25 years.

Kewley is correct in identifying that a key problem is the high attrition rates that account for continual leakage from the talent pipeline. Attrition also reduces the numbers of women reaching more senior positions, where they might be able to institute effective cultural change. However, Kewley's study gives little insight into the complexity of cultural issues that can make workplaces hostile environments for women and other marginalized groups. 'Getting in' is certainly an achievement, but if women's daily working lives then involve battling prejudice, put-downs and exclusion from 'the club', 'getting on' can feel impossible. Kewley rightly identifies metrics-driven criteria such as grant funding, publication, speaker invitations and so on as influential sources of bias, but to understand the all-pervasive power of gender discrimination we need to look beyond this. A cornerstone of understanding this situation is that gender relations are not fixed entities but are continuously and repetitively made in the routine practices of

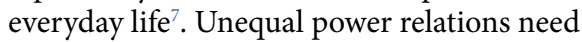
continual maintenance, such that sexism becomes a normal, rather than an aberrant aspect of the workplace: a 'business-as-usual' form of active discrimination that women confront every day. Furthermore, gender must be understood in intersection ${ }^{8}$ with other social identities such as inter alia race and ethnicity, social class, age and sexuality; all of which can combine to be sources of additional marginalization.

An embedded feature of 'business-as-usual' discrimination is social desensitization ${ }^{9}$, which increases the threshold of what counts as 'real' sexism, racism and so on. High-profile occurrences, such as leading scientists complaining that 'girls' in labs tend to fall in love with their male colleagues and cry when criticized ${ }^{10}$, or denying that physics suffers from male gender bias and 
criticizing affirmative-action policies ${ }^{11}$, can lead to a 'smokescreening' of the daily micro-aggressions by which sexism and discrimination are thoroughly embedded in the infrastructures of academic departments.

Recent years have seen the introduction of a raft of policy initiatives in astronomy, astrophysics and physics departments across Europe, the United States and, as Kewley's article reveals, Australia. These aim to better understand the factors contributing to women's under-representation, and tackle the systemic issues that work to exclude women from the disciplines ${ }^{12}$. Whereas the focus on institutional policies such as recruitment and promotion is important, these do not tackle the complex, subtle and often obscure ways in which bias and discrimination operate. To change cultures of marginalization and oppression, leadership that fully acknowledges the overt and covert ways in which these are operationalized is essential.

Lessons could be learned from women's comparative success in the social sciences. A recent study of UK social science funding found little difference between female and male application rates, success rates and grant size ${ }^{13}$, and looks to a broad cultural shift to explain this. The authors argue that, in tandem with higher levels of female representation in social science disciplines, there has been a move away from "conventional gender expectations" 14 that align with hierarchical, individualistic and competitive behaviours. This shift has been a conscious one: most social science disciplines actively engage with feminist research management practices, with "the guiding principles of consultation, collaboration and social equality, which have disrupted male hierarchies"15.

In a world still struggling with the COVID-19 pandemic, Kewley's study is timely. Actively tackling gender inequality is not only a matter of academic, social and economic justice, it is also critically important for the production of the creative and diverse thinking we are all relying upon to identify risks and accurate responses. Yet with the pandemic starkly revealing how inequalities are deepening still further for marginalized groups, extending the parameters of Kewley's study is imperative. Importantly, widening the variables to include in-depth investigation of other minoritized identities such as race and ethnicity, social class and caste, religion, sexual orientation, transgenderism and age, could reveal the ways these intersect to create double or triple binds ${ }^{8}$. We urgently need to prioritize and support research that promotes workforce diversity and integration for the benefit of both science and humanity.

Pauline Leonard (D) $₫$

Department of Sociology, Social Policy and
Criminology, University of Southampton, Southampton, UK.

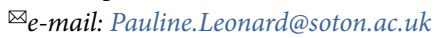

Published online: 19 April 2021

https://doi.org/10.1038/s41550-021-01348-6

References

1. Tuttle, S. Nat Astron. 1, 0154 (2017).

2. Urry, M. Nature 528, 471-473 (2015).

3. Kewley, L. J. Nat. Astron. https://doi.org/10.1038/s41550-02101341-z (2021)

4. Cochran, G., Singh, C. \& Wilkin, N. (eds) Volume 2109: Women in Physics. 6th IUPAP International Conference on Women in Physics (AIP, 2017).

5. Porter, A. M. \& Ivie, R. Women in Physics and Astronomy, 2019 (AIP, 2019); http://go.nature.com/2Nq4ZwD

6. Eran Jona, M. \& Nir, Y. in Volume 2109: Women in Physics. 6th IUPAP International Conference on Women in Physics (eds Cochran, G. et al.) 050022 (AIP, 2017).

7. Butler, J. in Performing Feminisms: Feminist Critical Theory and Theatre (ed. Case, S.-E.) 270-282 (Johns Hopkins Univ. Press, 1990).

8. Prescod-Weinstein, C. Nat. Astron. 1, 0145 (2017).

9. Breen, D. \& Meer, N. Identities 26, 595-613 (2019).

10. Nature 522, 255 (2015).

11. Castelvecci, D. Nature https://doi.org/10.1038/d41586-018-069130 (2018).

12. National Academies of Sciences, Engineering, and Medicine Promising Practices for Addressing the Underrepresentation of Women in Science, Engineering, and Medicine: Opening Doors. Proceedings of a Symposium-in Brief (The National Academies Press, 2020); https://doi.org/10.17226/25785

13. Boyle, P. J., Smith, L. K., Cooper, N. J., Williams, K. S. \& O’Connor, H. Nature 525, 181-183 (2015).

14. Glass, J. L., Sassler, S., Levitte, Y. \& Michelmore, K. M. Soc. Forces 92, 723-756 (2013).

15. Mauthner, N. \& Edwards, R. Gend. Work Organ. 17, 481-502 (2010)

Competing interests

The author declares no competing interests. 